\title{
Cost Effective Grid-Connected Inverter for a Micro Combined Heat and Power System
}

\author{
Ruoyang Du, Member, IEEE, and Paul Robertson
}

\begin{abstract}
This paper proposes a novel, cost effective grid-connected inverter for a domestic micro combined heat and power (micro-CHP) system. A high frequency $(\sim 12,000 \mathrm{rpm})$, high voltage $(\sim 425 \mathrm{Vdc})$ brushless DC (BLDC) machine is used as the generator. The output of the generator is injected into the grid through a novel grid-connected inverter, utilizing a digital algorithm for the implementation of a constant frequency hysteresis current control. This allows a simplified output filter with smaller components to be employed. A grid synchronization method has also been designed, based on a low-pass filter and a micro-controller to optimize/tune the output power factor. The proposed method is successfully applied to a $500 \mathrm{~W}, 230 \mathrm{~V}, 50 \mathrm{~Hz}$ grid-connected voltage source inverter (VSI) prototype, where the output of the VSI has been demonstrated to comply with the operating regulations of the domestic distributed power generation systems.
\end{abstract}

Index Terms- Grid-connected voltage source inverter (VSI), hysteresis current control (HCC), constant frequency control, distributed power generation, combined heat and power

\section{INTRODUCTION}

$\mathrm{M}$ ICRO combined heat and power (micro-CHP) is defined as an energy conversion unit with an electrical capacity below $15 \mathrm{~kW}$ that simultaneously generates heat and power [1]. Micro-CHP is a distributed power generation (DPG) technology, which can reduce greenhouse gas emissions from energy supply, increase decentralization of energy supply, improve energy security, avoid investment in and energy losses from electricity transmission and distribution networks, and potentially reduce energy cost to consumers [2], [3].

The overall efficiency of a micro-CHP system is normally around $90 \%$ [4], [5] or higher by utilizing wasted heat [6], [7]. Since the heat and electrical power demands in domestic buildings are closely correlated to each other [8], micro-CHP has been developed as an energy-efficient technology that simultaneously provides heat and electricity to households [1], which can potentially increase the overall efficiency of primary energy consumption for over $20 \%$ of the total [1], [6].

Manuscript received July 28, 2016; revised October 25, 2016 and January 4, 2017; accepted January 31, 2017.

Ruoyang Du is with Dynex Semiconductor Ltd, Doddington Road, Lincoln, Lincolnshire, UK (corresponding author phone: 01522502837 e-mail: ruoyang.du@cantab.net).

Paul Robertson is with the Electrical Engineering Division, University of Cambridge, Cambridge, CB3 OFA, UK (e-mail: par10@ cam.ac.uk).
Fuel cell (FC) micro-CHP [9] and electrical machine (EM) micro-CHP [10] are two main streams of micro-CHP technologies. FC micro-CHPs utilize a DC-DC converter cascaded with a DC-AC inverter, whereas EM micro-CHPs need an AC-DC converter cascaded with a DC-AC inverter.

A number of inverters have been developed for single phase FC and solar applications, including single phase full bridge inverters, single bus inverters with two paralleled half bridges, dual bus inverters with two split half bridges, $\mathrm{Z}$ source inverters, and LLCC resonant inverters [11],[12]. Among all the available technologies, the single phase full bridge inverter has a significant advantage in cost effectiveness due to the reduced component count, simple design and control [13].

The technological strategies for EM micro-CHPs are still emergent, and the state-of-the-art focuses on the system architecture, thermal analysis and prime mover optimization [14], [15] with relatively few papers discussing the inverters [10]. This paper contributes to this latter area by describing the development of a novel turbine driven micro-CHP, considering both the power electronics and thermo-dynamic characteristics interdependently. Transferable techniques from other small-scale distributed power generation systems, e.g. photovoltaic and wind turbine, have been taken into consideration [16], [17] where the most cost effective hysteresis current control (HCC) [18] method is selected and further developed for this specific application. The novelty of this paper includes i) a cost effective digital constant frequency HCC control algorithm with the minimized component count, ii) a customized grid synchronization unit with the ability to optimize/tune the output power factor, and, iii) a self-consistent system architecture where the mechanical and electrical characteristics are compatible with each other, wherein power transfer from the generator has been optimized through the use of series coupling capacitors to correct the high frequency power factor .

The cost of domestic micro-CHPs is expected to be around $\$ 4,000$ to $\$ 5000$ by 2020 [4]. This price is estimated as the marginal price to make this product commercially competitive compared with conventional boilers. However, the real prices of domestic micro-CHPs are currently far more expensive; typically $\$ 9,500$ to $\$ 27,000$ [19]. Hence the market penetration is currently very small, and there are only $\sim 1,110 \mathrm{CHP}$ schemes in operation in the UK in commercial, public administration, residential, transport and agricultural sectors combined [20].

Therefore, our research is concerned with the design of a low cost, robust and long lifetime micro-CHP, for which the total price can be within $\$ 4,500$ by 2020 . The proposed micro-CHP system is expected to produce around $9.5 \mathrm{~kW}$ of domestic 
heating, and $800 \mathrm{~W}$ of mechanical power which is converted into $500 \mathrm{~W}$ of electrical power fed into the grid. The input heat flow of the micro-CHP is $10.3 \mathrm{~kW}$, steam flow rate is $3.9 \mathrm{~g} / \mathrm{s}$, and the basic steam rate is $17.58 \mathrm{~kg} / \mathrm{kWh}$. The turbine is a single stage steam turbine with $20 \mathrm{~cm}$ diameter, for which the efficiency is around 30\%; the designed Rankine cycle is shown in Fig. 1.

We propose to achieve the new micro-CHP by incorporating a Rankine steam cycle and power electronics into an existing boiler package to minimize development costs. Currently, boiler prices in the UK normally range from $\$ 800$ to $\$ 2,600$ [21], which is below half the target $\$ 4,500$ price of micro-CHP by 2020 . This means that the additional cost of the proposed power electronics and steam cycle components shall be within $\$ 2,000$ to ensure the final price of the proposed micro-CHP falls within the right range.

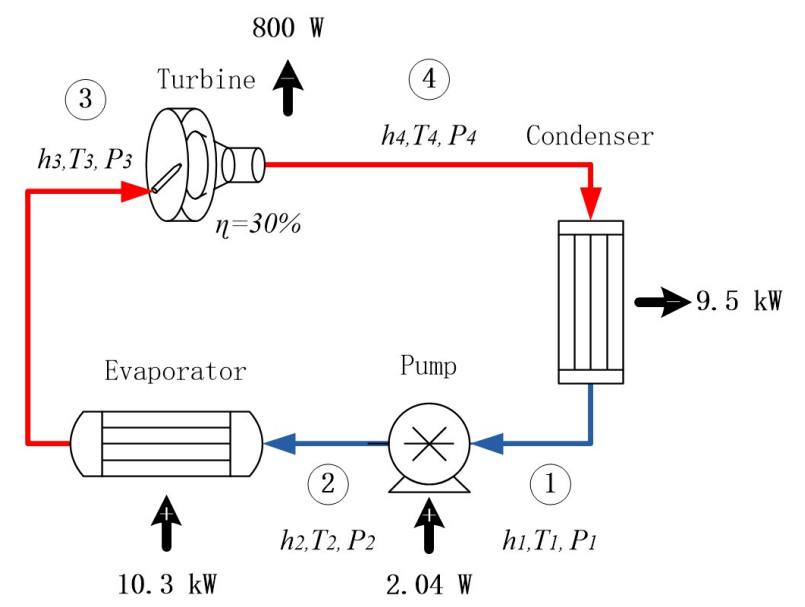

Fig. 1 The Rankine cycle of the micro-CHP

In our design, the one-off price of the power electronics is $~$ $\$ 300$ ( including generator $\sim \$ 50$, power electronic components $\sim$ \$135, and PCB board $\sim \$ 130$ ).

The high pressure evaporator is proposed as a 5-layer tube structure with optimized design for safety purposes, where the total material cost is less than $\$ 200$. The single-stage steam turbine with low pressure housing can be simply manufactured by a stamping process in stainless steel, which would not cost more than $\$ 200$ in volume. The water pump operates at a similar flow rate and pressure to the fuel pump in an oil-fired boiler and would cost less than $\$ 50$ in volume, based on a single unit costing $\sim \$ 75$ [22]. The low pressure condenser of the micro-CHP can use similar techniques to those in a conventional boiler to achieve a relatively low additional cost. Therefore, the total additional one-off cost of the proposed micro-CHP power electronics and steam cycle components is less than $\$ 800$, which indicates that a volume cost including fabrication and assembly of the overall micro-CHP looks viable within a budget of $\$ 4,500$ by 2020 .

Assuming the proposed micro-CHP operates 8 hours per day and 365 days per year, the total saving of the proposed micro-CHP is $\sim \$ 400$ per year if the feed-in tariff is applicable [23], or $\sim \$ 135$ if not.

This paper describes the power electronics design of the cost effective micro-CHP, which comprises: a 7-pole-pair brushless DC machine (based on a commercial BLDC motor used in RC models) which has been optimized to convert mechanical power from a $\sim 12,000 \mathrm{rpm}$ turbine into DC link electrical power; a novel single phase grid-connected inverter which has been designed using an innovative hysteresis current control (HCC) technique to inject up to $500 \mathrm{~W}$ into the UK mains grid; a grid synchronization module based on a low-pass filter and a variable micro-controller delay, which can achieve reliable phase alignment and power factor control.

\section{PRINCIPLES OF OPERATION}

\section{A. Structure of the system}

A two stage power conditioning circuit composed of an AC-DC converter and a DC-AC grid-connected inverter is used in this project, as shown in Fig. 2. A simple Schottky diode rectifier is used as the AC-DC converter, whereas a hysteresis controlled MOSFET bridge is used as the DC-AC voltage source inverter (VSI). A power decoupling polymer film capacitor $\mathrm{C}_{d c}$ is used as the energy buffer to maintain the DC link voltage and reduce the voltage ripples produced by the diode rectifier. An LCL filter is used to produce a sinusoidal current from the hysteresis controlled output of the VSI.

The rotational speed of the generator will be maintained at a constant value by setting the average value of $\mathrm{U}_{d c}$ as a feedback controlled constant, and the output current to the grid is varied according to the power available from the generator.

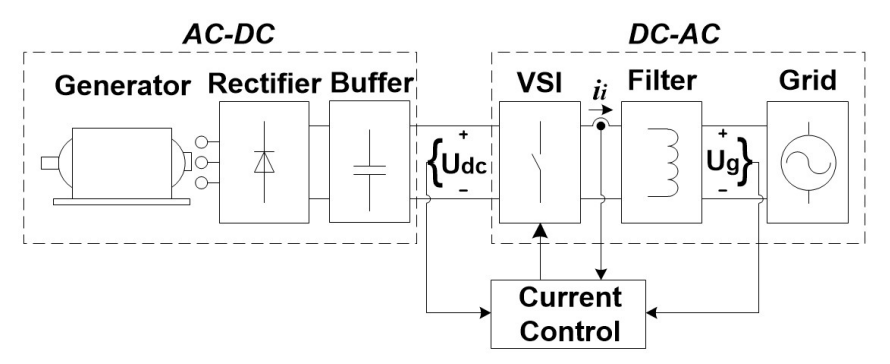

Fig. 2. Structure of the system

\section{B. AC-DC converter}

A commercial $\mathrm{Kv}=400 \mathrm{rpm} / \mathrm{V}$ brushless DC motor [24] has been rewound as a $25 \mathrm{rpm} / \mathrm{V}$ high voltage generator, which converts mechanical power from a $\sim 12,000 \mathrm{rpm}$ turbine into electrical power. Three $3 \mu \mathrm{F}$ polymer capacitors are used to cancel the inductive reactance of the generator windings at the rated frequency of about $1,400 \mathrm{~Hz}$ - this improves the efficiency of the power tranfer. Six Schottky diodes constitute a bridge rectifier which converts the 3-phase AC into the DC link voltage. A $40 \mu \mathrm{F}$ film capacitor is used as the DC link power decoupling energy buffer.

\section{DC-AC grid-connected inverter}

The DC-AC grid-connected inverter is designed as shown in Fig. 3. The input $\mathrm{DC}$ voltage $\mathrm{U}_{d c}$ comes from the output of the AC-DC converter. The MOSFET bridge is controlled by the output signals of the constant frequency HCC, which are used to produce the target $50 \mathrm{~Hz}$ sine wave current with the LCL filter, where $\mathrm{L}_{i}=2 \mathrm{mH}, \mathrm{L}_{g}=2 \mathrm{mH}, \mathrm{C}_{f}=1.5 \mu \mathrm{F}$, and $R_{d}=$ 
$5.1 \Omega$. The input current of the LCL filter $i_{i}$ is measured by a fluxgate closed-loop current transducer, the output of the current transducer is used as an input signal for the constant frequency HCC system. The performance of the fluxgate sensor is superior to Hall effect devices, showing an improved zero offset and response speed - both of which are important in this application.

Since high current, high inductance inductors are needed for the LCL filter, conventional ferrite inductors are not appropriate, as this material could not withstand $3 \mathrm{~A}$ at around $2 \mathrm{mH}$ without losing the high permeability within a small toroid package, and the inductor losses would be remarkably high under these circumstances. Therefore, an alternative 'iron powder' material was used in the core of the inductors, which has better performance under high current and high inductance situations and is relatively low cost - although it has a poorer high frequency response.

\section{MOSFET 1 MOSFET 2}

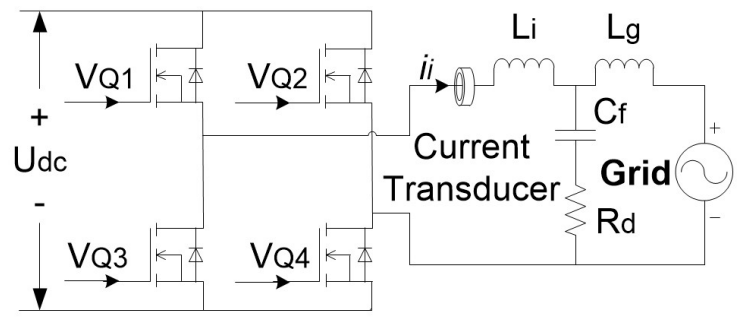

MOSFET 3 MOSFET 4

Fig. 3. DC-AC converter

\section{Grid synchronization unit}

The grid synchronization unit is shown in Fig. 4. Where the grid voltage $V_{\text {Grid }}$ is monitored by the difference amplifier, and filtered by a Butterworth low-pass filter. Then the filtered grid voltage $V_{\text {Grid_Filtered }}$ is compared with ground $(0 \mathrm{~V})$ to generate a square wave $V_{\text {Square }}$, which inherits the phase shift of $V_{\text {Grid_Filtered }}$. The phase shift of $V_{\text {Square }}$ is then compensated by a micro-controller delay, and another square wave $V_{\text {Trig }}$ is generated, which is used to trigger another micro controller to generate the reference signal $V_{r}$ for the output current $i_{i}$.

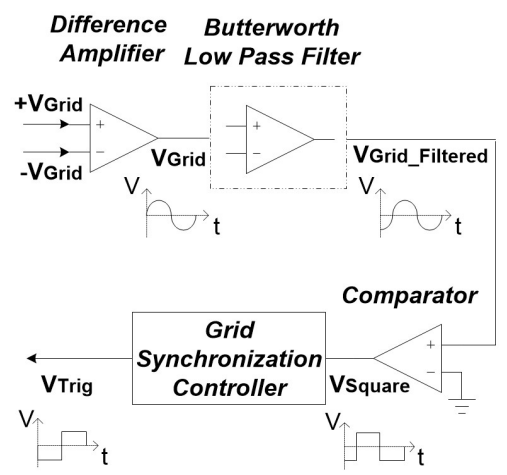

Fig. 4. Grid synchronization unit

\section{E. Hysteresis current control}

The output current of this system is based on a novel digital constant frequency hysteresis current control scheme, as shown in Fig. 5. This allows a high current control bandwidth to be achieved whilst using a low cost PIC micro-controller IC.

Where $\mathrm{U}_{\mathrm{dc}}$ is the DC voltage of the power supply, $V_{i}$ is the output voltage of the current transducer in Fig. 3, $V_{r}$ is the reference voltage, $V_{h}$ is the hysteresis band.

The inverter will produce a positive output voltage when the current error reaches the lower hysteresis limit. On the other hand, a negative output voltage is produced when the current error reaches the upper hysteresis limit.

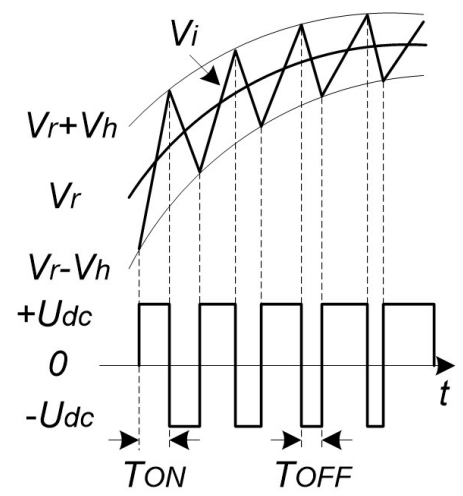

Fig. 5. Function diagram of hysteresis current control

In order to achieve a constant switching frequency, the hysteresis band should obey the following equation [25]:

$$
V_{h}=\frac{k}{4 f_{S} L_{i}} U_{d c}\left(1-m^{2} \cdot \sin ^{2} \theta\right)
$$

Where $\mathrm{k}=V_{i} / \mathrm{i}_{\mathrm{i}}$ is the current to voltage ratio of the current transducer, $\mathrm{f}_{\mathrm{S}}$ is the switching frequency, $\mathrm{L}_{\mathrm{i}}$ is the inverter side inductor in Fig. 3, $\mathrm{m}=\max \left(\mathrm{U}_{\text {grid }}\right) / \mathrm{U}_{\mathrm{dc}}$ is the modulation index, $\theta$ is the phase of the grid voltage.

Assuming a symmetrical bipolar hysteresis comparator is used to produce the control signal, as shown in Fig. 6.

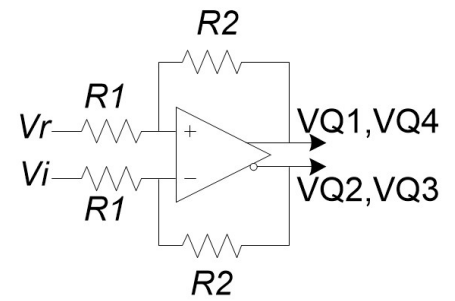

Fig. 6. Symmetrical bipolar hysteresis comparator

The hysteresis band can be expressed as [26]:

$$
\mathrm{V}_{\mathrm{h}}=\frac{\left(\mathrm{V}_{\mathrm{OH}}-\mathrm{V}_{\mathrm{OL}}\right) \mathrm{R}_{1}}{\mathrm{R}_{2}}
$$

Where $V_{O H}$ is the high output voltage of the comparator, and $V_{O L}$ as the low output voltage of the comparator. Substituting (2) into (1):

$$
R_{1}=\frac{k R_{2}}{4 f_{S} L\left(V_{o H}-V_{o L}\right)} U_{d c}\left(1-m^{2} \cdot \sin ^{2} \theta\right)
$$

Where $k, \mathrm{R}_{2}, \mathrm{f}_{\mathrm{S}}, \mathrm{L},\left(\mathrm{V}_{\mathrm{oH}}-\mathrm{V}_{\mathrm{oL}}\right)$ are constants for the proposed constant frequency $\mathrm{HCC}$, so $\mathrm{R}_{1}$ can be expressed as: 


$$
\mathrm{R}_{1}=\mathrm{C}_{\mathrm{h}} \mathrm{U}_{\mathrm{dc}}\left(1-\mathrm{m}^{2} \cdot \sin ^{2} \theta\right)
$$

Where $\mathrm{C}_{\mathrm{h}}$ is a constant:

$$
\mathrm{C}_{\mathrm{h}}=\frac{\mathrm{kR}_{2}}{4 \mathrm{f}_{\mathrm{S}} \mathrm{L}\left(\mathrm{V}_{\mathrm{oH}}-\mathrm{V}_{\mathrm{oL}}\right)}
$$

Therefore, a pair of programmable digital potentiometers is used to achieve this constant frequency HCC by achieving a variable $R_{1}$ as expressed in (4), as shown in Fig. 7.

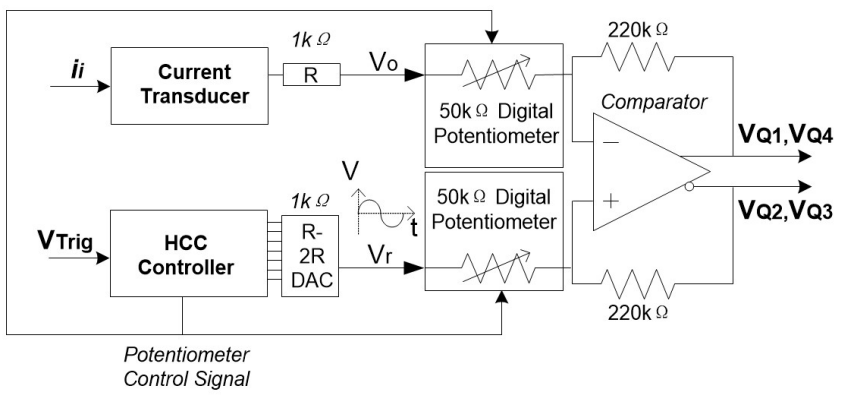

Fig. 7. Hysteresis current control

Where the PIC18F4520 generates the reference signal $V_{r}$ and the control signal of the potentiometers at the same time; these two signals are in-phase and synchronized with the grid by the trigger signal $V_{\text {trig }}$ from a grid synchronization unit in Fig. 4. The reference signal $V_{r}$ is sampled from a R-2R DAC, which converts the 8-bit parallel output of the micro-controller into an analogue sinusoidal wave. Since the equivalent resistance of the $\mathrm{R}(1 \mathrm{k} \Omega)-2 \mathrm{R}(2 \mathrm{k} \Omega) \mathrm{DAC}$ is $1 \mathrm{k} \Omega$, a $1 \mathrm{k} \Omega$ resistor is added between the current transducer and the $50 \mathrm{k} \Omega$ potentiometer to match the impedance of $V_{i}$ and $V_{r}$. Then the two input signals $V_{i}$ and $V_{r}$ pass through the $50 \mathrm{k} \Omega$ variable resistors, and compared by the comparator to generate the gate control signals: $V_{Q 1}, V_{Q 2}, V_{Q 3}, V_{Q 4}$.

\section{Power management}

During one grid period, the input power from the generator is relatively constant but the output power to the grid is sinusoidal, so power decoupling between the input and output is necessary in the electrical power generation system. Normally, the power decoupling is achieved by a buffer capacitor in the grid-connected inverter, for which a polymer film capacitor is preferable compared with an electrolytic capacitor, as the latter is the main limiting factor in the lifetime of a grid-connected inverter [17]. A high voltage DC link is normally necessary in order to substitute the electrolytic capacitor with a polymer film capacitor; which normally has higher rated voltage but lower capacitance. Since there is a high voltage DC link after the diode rectifier in this application, it lends itself to the use of a polymer film capacitor in the DC link - to both reduce the link voltage ripple and decouple the input and output powers.

Ideally the input power from the generator, which is provided by the steam turbine, is maintained at a steady value, and the output power of the generator is converted into an alternating current and injected at unity power factor to the grid voltage supply. Therefore, the instantaneous power injection is [27]:

$$
\begin{aligned}
P_{g}(t)=\widehat{U_{g}} \sin (\omega t) \cdot \widehat{I}_{g} & \sin (\omega t) \\
& =\frac{\widehat{U_{g}} \widehat{I}_{g}}{2}(1-\cos (2 \omega t))
\end{aligned}
$$

Where $\widehat{U_{g}}$ and $\widehat{I_{g}}$ are the peak values of the grid voltage and current, and $\omega$ is the grid voltage frequency in radians per second.

Since the input power is constant and the output power is fluctuating, there exists an energy fluctuation in the energy storage components of the electrical power generation system (EPGS). In a lossless EPGS, the input power $P_{\text {in }}=\frac{\widehat{U}_{g} \widehat{T}_{g}}{2}$. Therefore, the power mismatch is $\left(\widehat{U_{g}} \widehat{I_{g}} / 2\right) \cos (2 \omega \mathrm{t})$. Integrating with respect to time yields the energy fluctuation in the EPGS [27]:

$$
\Delta E=-\int \frac{\widehat{U}_{g} \widehat{I}_{g}}{2} \cos (2 \omega \mathrm{t}) \mathrm{dt}=-\frac{\widehat{U}_{g} \widehat{I}_{g}}{4 \omega} \sin (2 \omega t)
$$

Therefore, the maximum energy fluctuation in a $500 \mathrm{~W}$ system is:

$$
\Delta E_{\text {max }}=\frac{\widehat{U_{g} \widehat{I}_{g}}}{4 \omega}=\frac{P_{\text {in }}}{2 \omega}=\frac{500}{2 \times 2 \pi \times 50} \cong 0.796 \mathrm{~J}
$$

The decoupling capacitor in the high voltage DC link is used to store the energy [17],[27], which will result in voltage fluctuations in the DC link due to the energy fluctuation. Assuming the average voltage of the DC link capacitor is $U_{d c, \text { average }}$, and the maximum voltage is $U_{d c, \max }$, then the maximum energy buffered in the capacitor is:

$$
\Delta E_{c}=\frac{1}{2} C_{d c}\left(U_{d c, \text { max }}^{2}-U_{d c, \text { average }}^{2}\right)
$$

Neglecting the energy storages in other components which are much smaller, the DC link capacitance can then be calculated as:

$$
\begin{aligned}
& C_{d c}=\frac{P_{i n}}{\omega\left(U_{d c, m a}^{2}-U_{d c, \text { average }}^{2}\right)} \\
& =\frac{1.592}{\left(U_{d c, \text { max }}^{2}-U_{d c, \text { average }}^{2}\right)}
\end{aligned}
$$

Assuming $U_{d c, \min }=425 \mathrm{~V}$, and the breakdown voltage of the main components is $600 \mathrm{~V}$, we can select a $40 \mu \mathrm{F}, 900 \mathrm{~V}$ film capacitor which results in $U_{d c, \max }=574 \mathrm{~V}$.

Actually, the voltage fluctuation in a LTspice simulation was slightly smaller than the calculated value because some electrical energy has also been stored in other inductive and capacitive components, such as the winding inductance, LCL filter etc.

\section{SIMULATION}

The proposed grid-connected inverter has been successfully simulated in LTspice. The LTspice simulation circuit diagram of the whole system, including the generator, AC-DC converter, and DC-AC inverter, is shown in Fig. 8.

$\mathrm{V}_{A}, \mathrm{~V}_{B}, \mathrm{~V}_{C}$ are used to simulate the induced emf of the generator, for which the amplitudes are set as $280 \mathrm{~V}$ at $1450 \mathrm{~Hz}$ according to the experimental measurements. $\mathrm{R}_{A}=\mathrm{R}_{B}=$ $\mathrm{R}_{C}=6 \Omega$ are the measured winding resistances, and $\mathrm{L}_{A}=$ $\mathrm{L}_{B}=L_{C}=4.1 \mathrm{mH}$ are the measured winding inductances. 
The capacitors $\mathrm{C} 1, \mathrm{C} 2$ and $\mathrm{C} 3$ are $3 \mu \mathrm{F}$ film capacitors, which are used to cancel the inductive impedance of the generator windings at the rated frequency of about $1450 \mathrm{~Hz}$. The diodes D1, D2, D3, D4, D5, D6 constitute a rectifier which convert the 3 phase generator $\mathrm{AC}$ into the $\mathrm{DC}$ link voltage. The capacitor $\mathrm{C}_{d c}$ is a $40 \mu \mathrm{F}$ film capacitor, which is used as the power decoupling energy buffer. The MOSFET bridge is controlled by the output signals of the constant frequency HCC, which are used to produce the target $50 \mathrm{~Hz}$ sine wave current with the LCL filter, where $\mathrm{L}_{i}=2 \mathrm{mH}, \mathrm{L}_{g}=2 \mathrm{mH}, \mathrm{C}_{f}=$ $1.5 \mu \mathrm{F}$, and $R_{d}=5.1 \Omega$. The amplitude of the grid voltage is set as $325 \mathrm{~V}(230 \mathrm{Vrms})$, and the frequency is $50 \mathrm{~Hz}$.

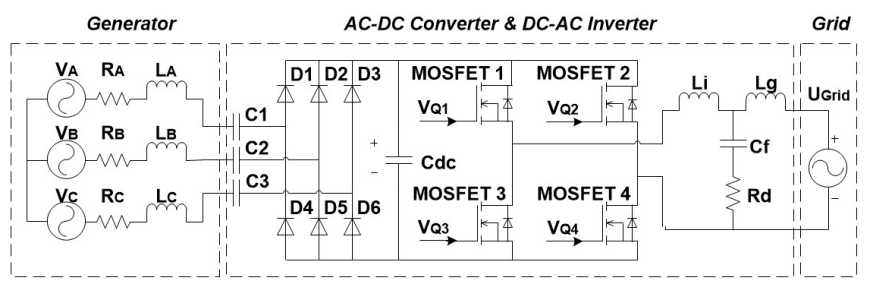

Fig. 8. Whole system circuit simulation diagram in LTspice

The LTspice simulated results of the constant frequency HCC (Fig. 5) signals $\mathrm{V}_{r}$ and $\mathrm{V}_{i}$ are shown in Fig. 9.

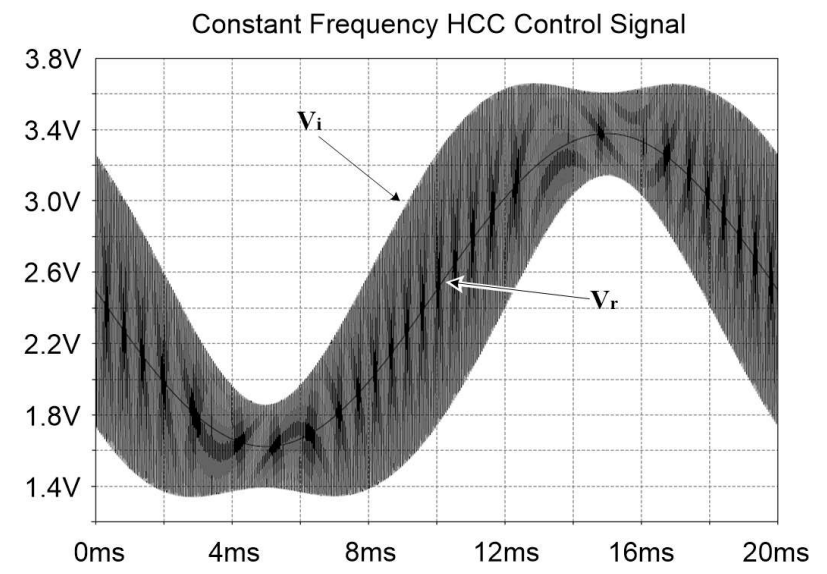

Fig. 9. Constant frequency HCC control signals in LTspice

The clean $50 \mathrm{~Hz}$ sine wave is the reference signal $\mathrm{V}_{r}$, which corresponds to the reference current $i_{r}$; and the high frequency triangular wave with variable amplitude is the hysteresis signal $\mathrm{V}_{i}$, which is correlated with the output current $i_{i}$ in the inductor $\mathrm{L}_{i}$.

It is clear that the hysteresis signal $\mathrm{V}_{i}$ has a variable amplitude in order to achieve a constant switching frequency. Actually, the frequency of $\mathrm{V}_{r}$ is from $23.46 \mathrm{kHz}$ (at the peak of $\mathrm{V}_{r}$ ) to $25.16 \mathrm{kHz}$ (at the mean of $\mathrm{V}_{r}$ ), which means there is $\mathrm{a} \pm 1.75 \%$ frequency variation. This small frequency variation may be caused by the variation of the DC link voltage $\mathrm{U}_{d c}$, or the impedance of $\mathrm{L}_{g}$ and $\mathrm{C}_{f}$. Fortunately, this small frequency variation does not cause any problems for the switches, LCL filter, or any other components in the power conditioning system.

The injected current in shown in Fig. 10, which has a target amplitude of $3.07 \mathrm{~A}$ in the simulation, with a phase shift of around $0.171 \mathrm{~ms}$, which represents around $3^{\circ}$ from the grid voltage. The peak-to-peak current ripple is from $17.4 \mathrm{~mA}$ at the peak of the output current to $61.3 \mathrm{~mA}$ at the mean of the output current, which is from $\sim 0.28 \%$ to $\sim 1.0 \%$ of the output current. Therefore, a power factor of 0.97 is predicted with a maximum total current distortion within $1.0 \%$, which are within the design regulations for distributed power generation systems [28], [29].

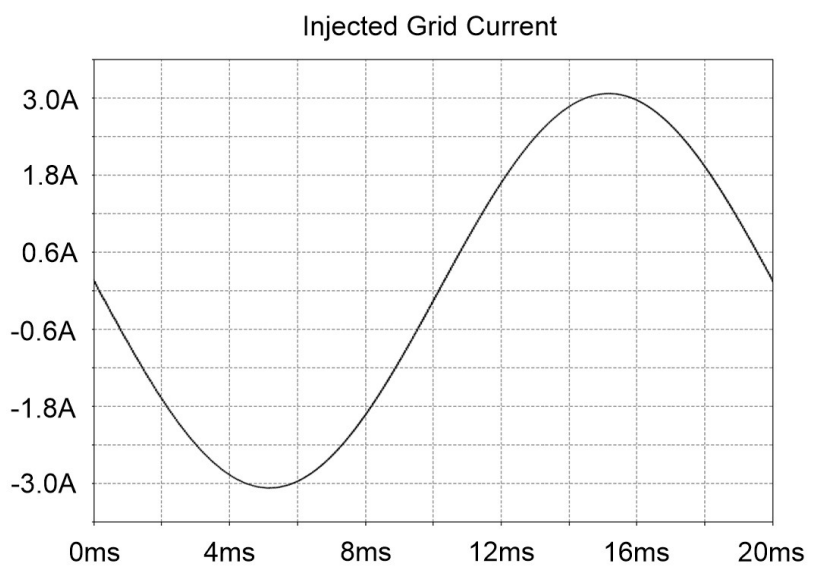

Fig. 10. Injected grid current in LTspice

The fast Fourier transform of the injected grid current in LTspice is shown in Fig. 11. The calculated frequency range is from $50 \mathrm{~Hz}$ to $6.55 \mathrm{MHz}$, where the reference attenuation is $6.73 \mathrm{~dB}$ at $50 \mathrm{~Hz}$.

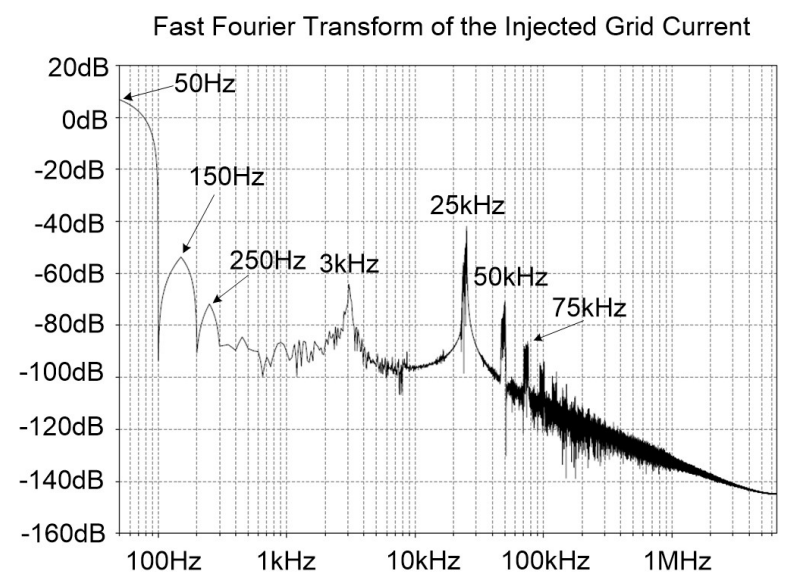

Fig. 11. Fast Fourier transform of the injected grid current in LTspice

It can be seen that there are 2 peaks around the $50 \mathrm{~Hz}$ fundamental frequency, which are the $3^{\text {rd }}(150 \mathrm{~Hz})$ and $5^{\text {th }}(250$ $\mathrm{Hz}$ ) harmonics of the grid frequency, for which the amplitudes are $-54 \mathrm{dBA}$ and $-72 \mathrm{dBA}$, respectively. There are around 5 peaks around the switching frequency, where the three most significant are $25 \mathrm{kHz}, 50 \mathrm{kHz}$, and $75 \mathrm{kHz}$, all of which have amplitudes below the specified limits.

\section{EXPERIMENTAL TESTS}

A photograph of the test rig is shown in Fig. 12, and the schematic diagram is shown in Fig. 13. 


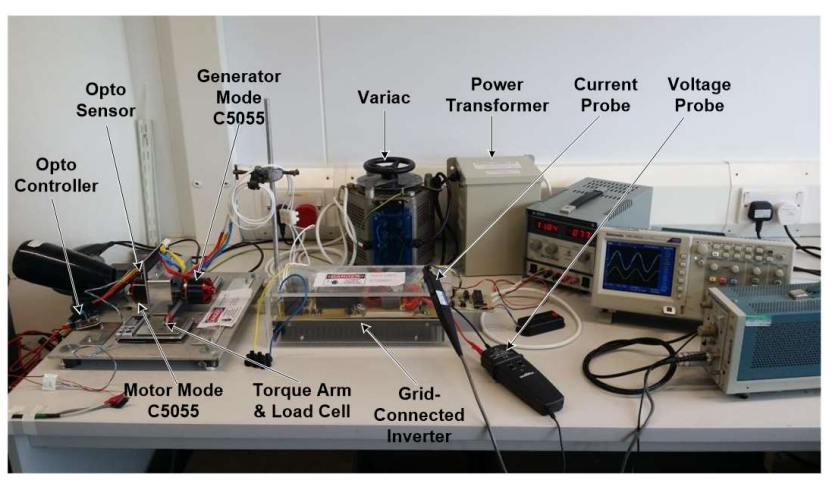

Fig. 12. Photograph of the test rig of the grid-connected inverter with generator

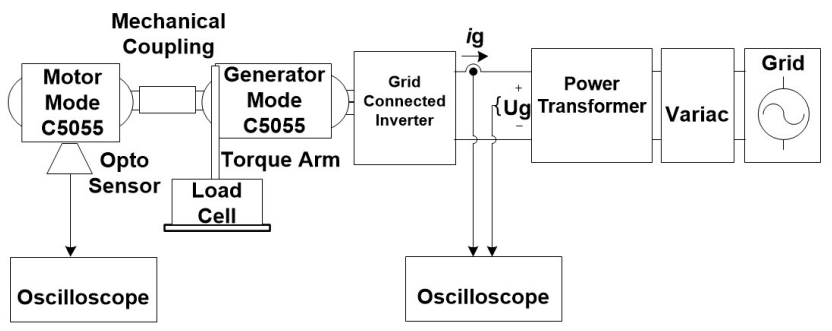

Fig. 13. Test rig of the grid-connected inverter with generator

The back-to-back test rig includes a pair of motors, where one of the motor emulates a turbine whilst the other works as a generator. The generator is connected to the grid-connected inverter through the bridge rectifier. The grid-connected inverter is connected to the grid through an isolating transformer and a Variac for test purposes - they are not necessary components in a final commercial product. The input mechanical power was measured by the torque load cell and the opto speed sensor, and the output electrical power is measured with the digital oscilloscope and calibrated voltage and current probes.

The overall efficiency of the system (defined as the electrical output power fed to the grid divided by the turbine input mechanical power) is measured as $\sim 65 \%$, where the grid connected inverter is $80 \% \sim 85 \%$ and the generator $75 \% \sim 80 \%$. The relative proportions of the total system losses are: Generator: 44\%, LCL filter: 30\%, MOSFETs: 22\%, Misc. 4\% where the various components are operated at near their maximum rated currents, in order to minimize overall cost.

The efficiency of the inverter could be improved by using over-sized, lower-loss switching transistors, advanced gate drive technology and a larger filter inductor volume. It is also worth noting that in a CHP system of this type, power dissipation which can be thermally coupled to the water inlet (such as MOSFET losses via the heatsink) is not necessarily 'wasted' but rather contributes to the thermal output - hence efficiency optimization has been secondary to cost minimization in this project. Furthermore, a specially designed (larger) generator could also have an improved efficiency compared to the mass-produced brushless DC motor currently selected, however, it too would cost more.

The test results of the grid synchronization unit and the grid-connected inverter are described as follows:

\section{A. Grid Synchronization Unit Test}

The grid synchronization unit has two main functions: filtering the high frequency noise and harmonics; producing a trigger signal which is synchronized with the grid voltage.

In terms of the filtering function, this Butterworth filter is not only able to attenuate the grid harmonics (as shown in Fig. 14), but also to substantially attenuate the switching noise at high frequency. In order to verify its capability, a sampled grid voltage $V_{\text {Grid }}$ with severe high frequency switching noise has been supplied to the Butterworth filter, and the output signal is clean and clear as shown in Fig. 15, and thus should allow reliable phase tracking.

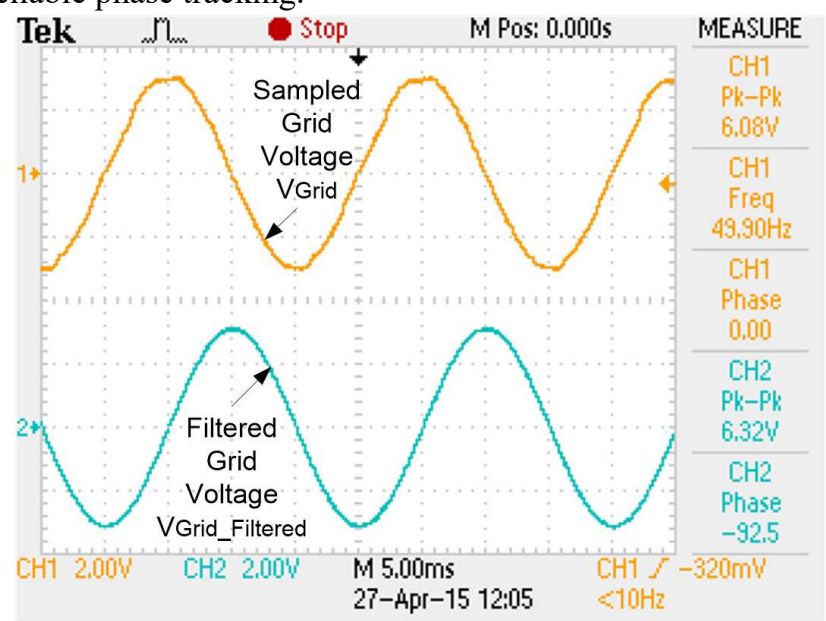

Fig. 14 Filtered Grid Voltage

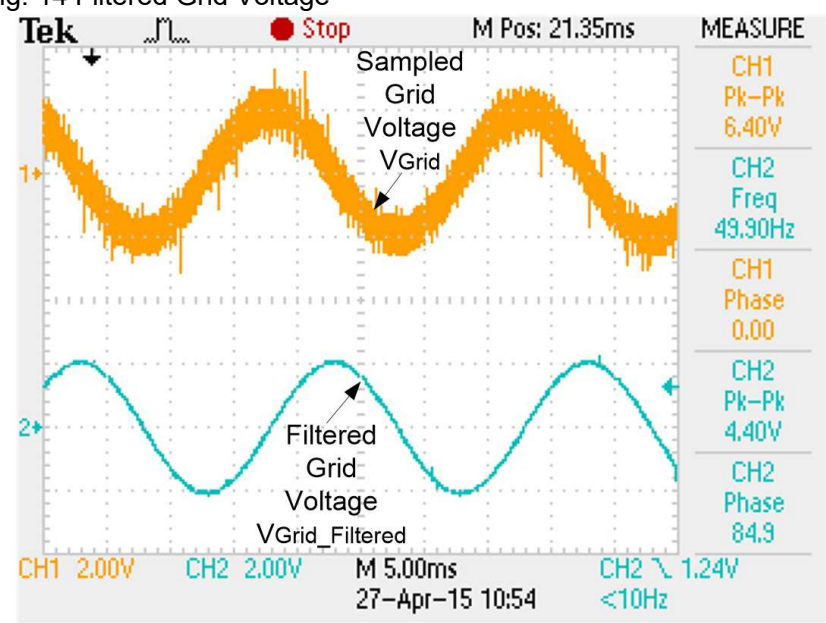

Fig. 15. Filtered Grid Voltage with Switching Noise

In terms of the synchronization function, the measured phase delay of the Butterworth filter is $-92.2^{\circ}(5.12 \mathrm{~ms})$, and the trigger signal $V_{\text {Trig }}$ is generated by adding around $-88^{\circ}(4.88$ $\mathrm{ms}$ ) to the $V_{\text {Square }}$ signal timing. Therefore, the trigger signal $V_{\text {Trig }}$ has around $-180^{\circ}$ phase shift relative to the grid voltage $V_{\text {Grid }}$.

Since there is $-180^{\circ}$ phase shift between $V_{\text {Grid }}$ and $V_{\text {Trig }}$, another $180^{\circ}$ phase shift is added in the calculation for the look-up table for the reference signal $V_{r}$, in order to align $V_{r}$ in phase with $V_{\text {Grid. }}$. The generated $V_{r}$ is shown in Fig. 16. 


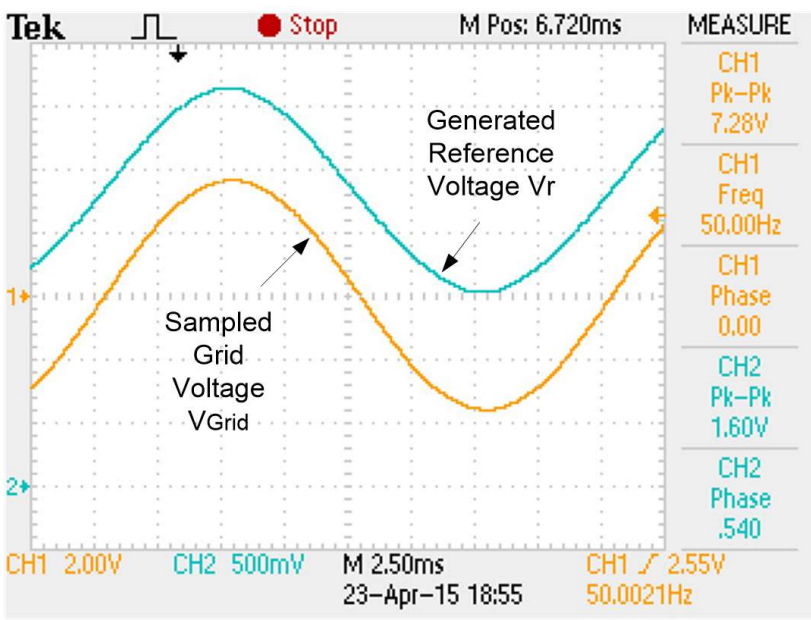

Fig. 16. Grid Voltage and Generated Reference Voltage

We can see that there is little phase shift between the grid voltage $V_{\text {Grid }}$ and the reference signal $V_{r}$. Also, since the phase shift of $V_{r}$ can actually be adjusted by any degree, the LCL filter induced power factor change can easily be compensated by this grid synchronization module.

\section{B. DC-AC Grid-Connected Inverter Test}

This DC-AC grid-connected inverter with the proposed constant frequency HCC has been successfully tested under the grid voltage of the UK $(\sim 230 \mathrm{Vrms})$ with the rated output current of around 3.06 A amplitude, as shown in Fig. 17.

In order to identify the amplitude of the harmonics, an FFT analysis on the averaged current waveform of 3.06A amplitude is shown in Fig. 18.

We can see that the $2^{\text {nd }}, 3^{\text {rd }}, 4^{\text {th }}, 5^{\text {th }}, 6^{\text {th }}$ harmonics are $-37 \mathrm{~dB}$, $-45 \mathrm{~dB},-50 \mathrm{~dB},-49 \mathrm{~dB},-51 \mathrm{~dB}$ relative to the fundamental 50 Hz value, which represent $1.45 \%, 0.55 \%, 0.31 \%, 0.29 \%$ and $0.35 \%$ distortion respectively.

Therefore, the total harmonic distortion (THD) at $3.06 \mathrm{~A}$ amplitude can be calculated as:

THD $=\frac{\sqrt{V_{2}^{2}+V_{3}^{2}+V_{4}^{2}+V_{5}^{2}+V_{6}^{2}}}{V_{1}}$

$=\sqrt{(1.45 \%)^{2}+(0.55 \%)^{2}+(0.31 \%)^{2}+(0.29 \%)^{2}+(0.35 \%)^{2}}$ $\cong 1.65 \%$

The total harmonic fulfils the standards IEEE 1547 and EN 50160 [28], [29]. This means that the quality of the injected current is acceptable when the system is working at the rated output current condition.

Additionally, an FFT analysis on the averaged current waveform of 1A amplitude has also been conducted; with similar findings.

Comparing these results with the values given in EN61000-3-2 for a Class A system, normalized according to GR83/2 for a $500 \mathrm{~W}$ inverter, the even and odd harmonics are around $20 \%$ and $5 \%$ respectively of the prescribed limits.

The DC injection was measured at $<8 \mathrm{~mA}$; below the $<2 \mathrm{~kW}$ inverter limit of $20 \mathrm{~mA}$, and the power factor was $>0.97$. GR83/2 and EN50438 standards also require the provision of $\pm 0.1 \mathrm{~Hz}( \pm 0.2 \%)$ frequency and $\pm 1.5 \%$ voltage monitoring resolution in grid protection functions, including islanding, if the grid supply should fail or drift out of specification.

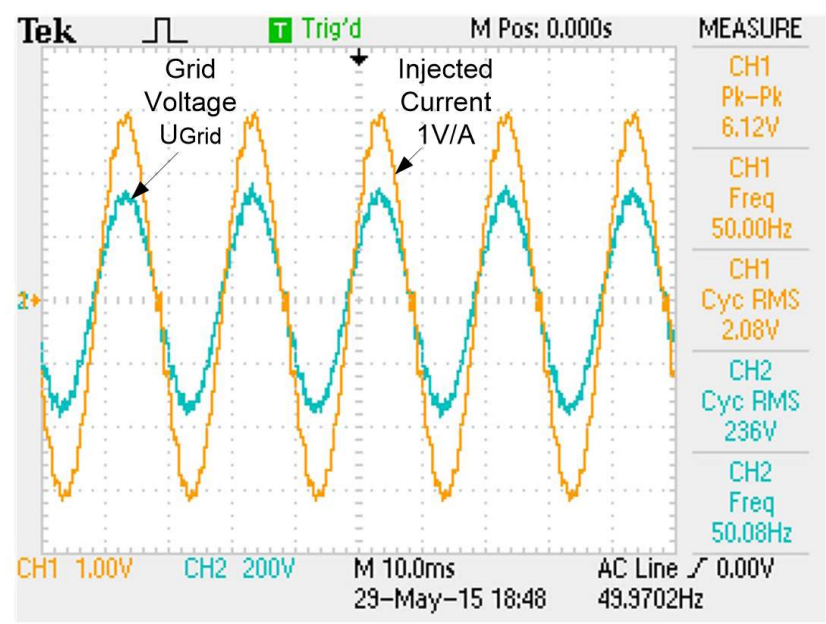

Fig. 17. Output Test of Grid-Connected Inverter

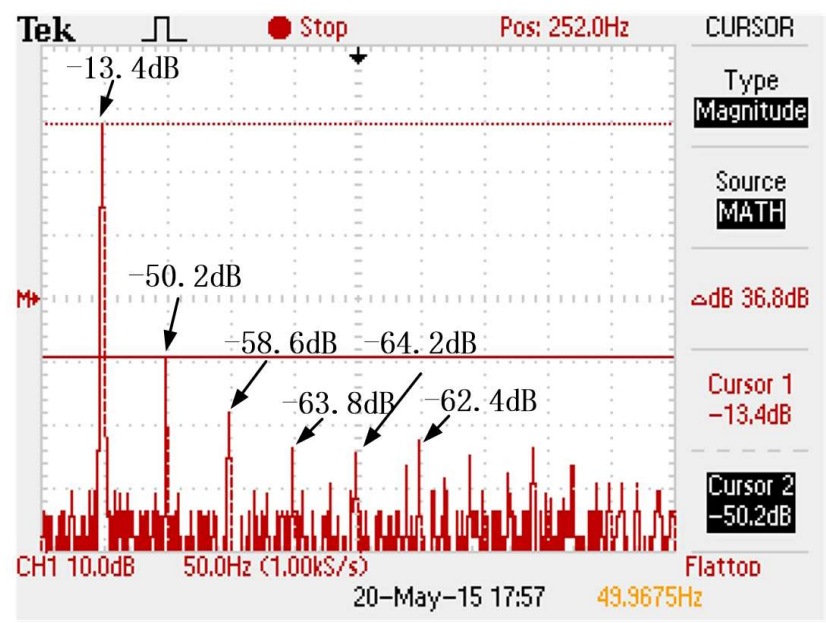

Fig. 18. FFT of the output current with $3.06 \mathrm{~A}$ amplitude

Whilst these have not all been fully implemented in our experimental system, there should be confidence that such functionality can be achieved within the architecture proposed. The PIC microcontroller has a 10-bit ADC, which when scaled to provide a peak range of $1.2 \times$ the peak-to-peak grid voltage, gives a suitable resolution of $0.33 \%$ (the circuit architecture 2 provides scaled signal voltages for both line voltage and current, which can be fed to the PIC). The 10 MIPS processor core can provide software timing with $5 \mu$ s increments on the $20 \mathrm{~ms}$ grid synchronization square wave signal, achieving $0.025 \%$ resolution. For illustration, the current injection control loop which handles the sine-wave synthesis and setting the comparator hysteresis dynamically in $1.5^{\mathrm{o}}$ increments requires approximately 1 MIPS (i.e. $10 \%$ of the PIC capability), thus substantial spare processor capability exists to handle the other functions. Alternatively, a 70 MIPS, 16-bit PIC 24EP128GP device could be used; costing $<\$ 2$ each.

\section{CONCLUSION}

This paper proposes a reliable, low cost and long life-time mains power generation system which can be implemented within domestic boilers to construct a (micro-CHP) system. This micro-CHP system is expected to produce around $10 \mathrm{~kW}$ of domestic heating output and $300-500 \mathrm{~W}$ of electrical power fed into the grid. The total one-off price for the electrical 
components in this power generation section is $\sim \$ 300$ in the UK, which would fall considerably if mass produced in the Far East for example. When implemented in a domestic boiler with a low cost, single-stage steam cycle turbine, this system has the potential to reduce the cost of a commercial micro-CHP to a target price of $<\$ 4500$ by 2020 .

In terms of the power electronics design, the basic $\mathrm{HCC}$ method has been modified to include two additional digital potentiometers, varied by a micro-controller, to restrain the switching frequency of the inverter over a narrow bandwidth, and grid synchronization is based on a low-pass filter and a variable micro-controller delay to achieve reliable phase alignment and power factor control, even in the presence of grid harmonic distortion. These two features have been demonstrated to operate effectively in the grid-connected inverter, which has the advantages of simplicity and low costs compared with the conventional methods; typically a feed-forward method with a phase-locked loop [25]. Also, the output of the grid-connected inverter has been demonstrated to comply with the operating standards IEEE 1547 and EN 50160 [28], [29].

\section{REFERENCES}

[1] M. Houwing, R. R. Negenborn, and B. De Schutter, "Demand response with micro-CHP systems," Proc. IEEE, vol. 99, no. 1, pp. 200-213, Jan. 2011.

[2] A. D. Hawkes and M. A. Leach, "Cost-effective operating strategy for residential micro-combined heat and power," Energy, vol. 32, no. 5, pp. 711-723, May 2007.

[3] M. A. Ehyaei and A. Mozafari, "Energy, economic and environmental (3E) analysis of a micro gas turbine employed for on-site combined heat and power production," Energy Build., vol. 42, no. 2, pp. 259-264, Feb. 2010.

[4] A. D. Hawkes and M. A. Leach, "On policy instruments for support of micro combined heat and power," Energy Policy, vol. 36, no. 8, pp. 2973-2982, Aug. 2008.

[5] V. Kuhn, J. Klemeš, and I. Bulatov, "MicroCHP: Overview of selected technologies, products and field test results," Appl. Therm. Eng., vol. 28, no. 16, pp. 2039-2048, Nov. 2008.

[6] U.S . Environmental Protection Agency Combined Heat and Power Partnership, "Catalog of CHP technologies," 2015.

[7] P. A. Pilavachi, "Mini- and micro-gas turbines for combined heat and power," Appl. Therm. Eng., vol. 22, no. 18, pp. 2003-2014, Dec. 2002.

[8] A. Peacock and M. Newborough, "Controlling micro-CHP systems to modulate electrical load profiles," Energy, vol. 32, no. 7, pp. 1093-1103, Jul. 2007.

[9] S. Sumiyoshi, H. Omori, and Y. Nishida, "Power conditioner consisting of utility interactive inverter and soft-switching dc-dc converter for fuel-cell cogeneration system," in 2007 Power Conversion Conference - Nagoya, 2007, pp. 455-462.

[10] M. Morandin and S. Bolognani, "Nano-CHP for home application: Control and electric drive design," in 2012 IEEE International Energy Conference and Exhibition (ENERGYCON), 2012, pp. 134139.

[11] A. Kirubakaran, S. Jain, and R. K. K. Nema, "A review on fuel cell technologies and power electronic interface," Renew. Sustain. Energy Rev., vol. 13, no. 9, pp. 2430-2440, Dec. 2009.

[12] J. Ardashir, M. Sabahi, S. Hosseini, F. Blaabjerg, E. Babaei, and G. Gharehpetian, "A single-phase transformerless inverter with charge pump circuit concept for grid-tied PV applications," IEEE Trans. Ind. Electron., vol. PP, no. 99, 2016.

[13] A. Kirubakaran, S. Jain, and R. K. K. Nema, "A review on fuel cell technologies and power electronic interface," Renew. Sustain. Energy Rev., vol. 13, no. 9, pp. 2430-2440, Dec. 2009.

[14] M. Liu, Y. Shi, and F. Fang, "Combined cooling, heating and power systems: A survey," Renew. Sustain. Energy Rev., vol. 35, pp. 1-22, 2014.
[15] S. Murugan and B. Horák, "A review of micro combined heat and power systems for residential applications," Renew. Sustain. Energy Rev., vol. 64, pp. 144-162, 2016.

[16] F. Blaabjerg, R. Teodorescu, M. Liserre, and A. V. Timbus, "Overview of control and grid synchronization for distributed power generation systems," IEEE Trans. Ind. Electron., vol. 53, no. 5, pp. 1398-1409, Oct. 2006.

[17] S. B. Kjaer, J. K. Pedersen, and F. Blaabjerg, "A review of single-phase grid-connected inverters for photovoltaic modules," IEEE Trans. Ind. Appl., vol. 41, no. 5, pp. 1292-1306, Sep. 2005.

[18] M. P. Kazmierkowski and L. Malesani, "Current control techniques for three-phase voltage-source PWM converters: a survey," IEEE Trans. Ind. Electron., vol. 45, no. 5, pp. 691-703, 1998.

[19] Jeremy Harrison, "Micro CHP products," 2011. [Online]. Available: http://www.microchap.info/micro_chp_products.htm.

[20] Local Government Association, "Combined heat and power," 2015. [Online]. Available: http://www.local.gov.uk/climate-change/-/journal_content/56/10180 /3510573/ARTICLE

[21] M. Knight, "Boiler Prices," Which, 2016. [Online]. Available: http://www.which.co.uk/reviews/boilers/article/boiler-prices.

[22] Air Dynamics Heating \& Cooling LLC, "Oil furnace fuel pumps," 2016. [Online]. Available: http://www.heatingandcoolingwarehouse.com/Oil_Furnace_Fuel_P umps_s/69.htm.

[23] Energy Saving Trust, "Feed-in tariff scheme," 2014. [Online]. Available:

http://www.energysavingtrust.org.uk/domestic/content/feed-tariff-sc heme. [Accessed: 10-Jun-2015].

[24] R. Du and P. Robertson, "Dynamic Jiles-Atherton model for determining the magnetic power loss at high frequency in permanent magnet machines," IEEE Trans. Magn., vol. 51, no. 6, pp. 1-10, Jun. 2015.

[25] L. Malesani, P. Mattavelli, and P. Tomasin, "Improved constant-frequency hysteresis current control of VSI inverters with simple feedforward bandwidth prediction," IEEE Trans. Ind. Appl., vol. 33, no. 5, pp. 1194-1202, 1997.

[26] R. Du, "The mains power generation section of a domestic micro combined heat and power system," University of Cambridge, 2015.

[27] C. Rodriguez and G. A. J. Amaratunga, "Long-lifetime power inverter for photovoltaic AC modules," IEEE Trans. Ind. Electron., vol. 55, no. 7, pp. 2593-2601, Jul. 2008.

[28] N. Golovanov, G. Lazaroiu, M. Roscia, and D. Zaninelli, "Power quality assessment in small scale renewable energy sources supplying distribution systems," Energies, vol. 6, no. 2, pp. 634-645, Jan. 2013.

[29] N. Kelly, M. Sasso, G. Angrisani, and C. Roselli, "Impact of microgeneration systems on the low-voltage electricity grid," 2014.

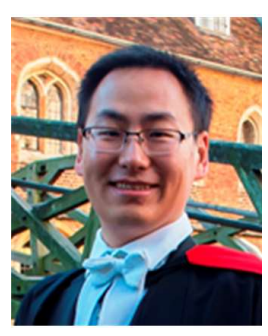

Ruoyang Du (S'14, M'16) received the B. Eng. degree in electronic information engineering from Zhejiang University, Zhejiang, China, in 2010, and MPhil and PhD degrees in electrical engineering from the University of Cambridge, UK, in 2012 and 2016, respectively. He has been working in the R\&D centre of Dynex Semiconductors Ltd, Lincoln, UK since 2016. His research interests include micro-CHP systems, electric vehicle traction drives, and artificial intelligence for physics and engineering applications.

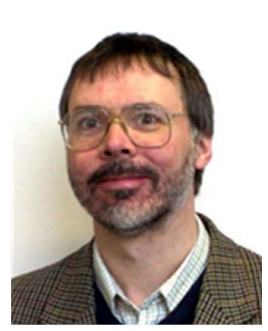

Paul Robertson received the BA degree in Electrical Sciences from the University of Cambridge, Cambridge, UK in 1984 followed by a $\mathrm{PhD}$ on thin film electronics in 1987 from the same institution.

From 1987 to 1995 he worked at the PA Technology Center in Melbourn before returning to the faculty in the Engineering Department at the University of Cambridge. He is author of over 50 technical papers and patents. His research interests include CHP systems, hybrid-electric propulsion for aircraft and electromagnetic sensors for instrumentation. He has been a Chartered Engineer and IET Member since 1995. 